\title{
Safeguarding the many guises of farmed fish welfare
}

\author{
J. F. Turnbull ${ }^{1, *}$, S. Kadri ${ }^{2}$ \\ ${ }^{1}$ Institute of Aquaculture, University of Stirling, Stirling, FK9 4LA, UK \\ ${ }^{2}$ Fish Biology Group, Institute of Biomedical \& Life Sciences, Graham Kerr Building, \\ University of Glasgow, Glasgow, G12 8QQ, UK
}

\begin{abstract}
There has been a great deal of debate and sometimes open hostility between people with differing approaches to the welfare of farmed animals, but relatively little progress towards compromise or consensus. It has been suggested that progress has been inhibited by a fundamental lack of common ground; people are debating different questions. Compromise or consensus can only be achieved through understanding and this in turn requires effective presentation of information and constructive dialogue. In this paper we adapt a previously published framework to present and evaluate information relevant to a wide range of definitions of fish welfare. Through improved understanding we will increase our capacity to safeguard many aspects of welfare of farmed fish, satisfying the demands of more but not all stakeholders.
\end{abstract}

KEY WORDS: Welfare $\cdot$ Farmed fish $\cdot$ Safeguarding $\cdot$ Evaluation $\cdot$ Stakeholders

Resale or republication not permitted without written consent of the publisher

\section{INTRODUCTION}

The issue of farmed fish welfare presents us with many challenging questions: what is it, how can we assess it, what is its relative importance and how can we safeguard it? Many of these challenges have already been addressed to a greater or lesser extent for terrestrial animals. However, we cannot simply transfer this wisdom to aquaculture, since teleosts and other aquatic animals present novel and very significant challenges. Against a background of poor understanding and agreement on these central issues there is increasing concern regarding the welfare of farmed fish (Lymbery 2002, Conte 2004, Huntingford et al. 2006).

Three areas of understanding need to be developed to effectively safeguard farmed fish welfare. These are an understanding of the biological processes involved, society's moral concerns and how conflicting interests can be balanced (teleost, environmental and human) (Huntingford et al. 2006). Since one's background inevitably affects one's perspective on these and many other issues, people with different backgrounds need to work together to improve understanding. Biologists, veterinarians and farmers can contribute to the under- standing of biological and applied aspects of fish welfare, but they are not necessarily qualified to make useful contributions to the moral philosophical or ethical arguments; this is the domain of the ethicist or moral philosopher and others. However, eventually all stakeholders and society at large must decide how we should treat farmed fish.

Understanding the various perspectives, beliefs, feelings and data is essential if we are to move towards compromise or consensus. Biological fish welfare research produces empirical information intended to inform moral decisions (i.e. differentiating right from wrong). Only if scientists directing that research are cognizant of the moral context can scientific studies contribute to moral decisions. For example, data on the stress levels associated with husbandry practices do not tell us whether those practices are morally acceptable (Jensen 1996).

In this paper we examine how demands to safeguard the welfare of farmed fish can be met even in the absence of consensus over key questions. We also adapt a previously published framework (Fraser et al. 1997) to present and evaluate information relevant to a wide range of definitions of fish welfare. 


\section{DEFINING FISH WELFARE}

Agreeing on a definition of fish welfare is a very challenging task, which has received a great deal of attention in recent years. A major obstacle to progress has been a lack of effective communication between people with an applied background in fish biology and philosophers. Fortunately, some people have made significant advances towards effective communication (e.g. Fraser 1999, Appleby 1999).

Concepts of animal welfare can be grouped into 3 categories: feelings-, function-, and rights (or nature)-based definitions. Briefly, the first is concerned with the subjective experience of the animal and implies that it is capable of suffering. In this category, good welfare is defined as the absence of negative feelings and the presence of positive feelings. The second category defines good welfare as good health and normal biological function or the absence of disease. The third requires that an animal is allowed to express its natural behaviour and live in an environment to which it is adapted.

Three hypothetical diets can exemplify infringement of the 3 categories of welfare. One diet is inadequate in volume but fulfils all the nutritional requirements of the animal; this may lead to feelings of hunger (negative feelings). A second may adequately satisfy the hunger but be deficient in some nutrients, leading to malnutrition (impaired function and perhaps later negative feelings); a third diet may satisfy hunger and nutritional requirements but prevent the animal from expressing its natural predatory nature (failure to lead a natural life) (adapted from Ewbank1988).

In the absence of consensus on a definition of welfare, one approach has been to adopt a single perspective on fish welfare, for example, feelings-based definitions (Huntingford et al. 2006) or function-based definitions (McGlone 1993 discussed by Fraser et al. 1997). Such simplification may be necessary in order to achieve practical objectives, and in many cases the 3 categories (negative feelings, poor function and inability to lead a natural life) accompany one another. However, aspects of good welfare which some people consider important may be omitted as a result of such simplification.

Even the simplified feelings-based approach has not been without problems when applied to fish. This approach assumes that fish have the capacity to suffer, an issue that has been the subject of debate (e.g. Rose 2002, Sneddon et al. 2003a,b, Braithwaite \& Huntingford 2004, Chandroo et al. 2004). While there is still no conclusive evidence for or against the capacity of fish to suffer, some have expressed the opinion that fish can suffer, but that the experience is different from that of primates and other higher vertebrates.

Equating welfare with suffering presents the ethical question: If they cannot suffer, should we be concerned with their welfare? Rose (2002) argued that fish are not capable of suffering but maintained that we still have a duty of respectful and responsible stewardship. Broom $(1991 \mathrm{a}, \mathrm{b})$ proposed that injury and disease are evidence of reduced welfare whether the animal is aware of them or not (a function-based approach to welfare). If we were only concerned with suffering there would only be purely pragmatic reasons for preventing injury to an animal which was unaware of injury or incapable of subjective experience. Such a pragmatic attitude is reflected in the treatment of many fish. For example, many wild caught fish are gutted immediately after they are landed, whether dead or alive. The Alaska Seafood Marketing Institute recommend that 'Gutting, where practical, should take place as soon as the fish come on deck' (Anonymous 2006). However, the view of fish welfare expressed by other individuals and governments is wider than purely pragmatic concerns or preventing suffering. As part of an ongoing project funded by the UK Government Department for Environment, Food and Rural Affairs (DEFRA), we discussed welfare with a wide range of stakeholders in the UK trout industry (North et al. in press). From this exercise it was clear that the concerns of stakeholders, including farmers, were not limited to purely production- or feelings-based concerns. If welfare is not just feelings how should we approach it?

While it may be tempting to look at fish welfare in terms of what can be measured and controlled, this effectively reduces welfare to an empirical concept. Fraser et al. (1997) identified 2 kinds of distortions that may arise when scientists define welfare: (1) they reduce welfare to an empirical concept and (2) they fail to recognise the influence of their own ethical perspective. Rather than scientific curiosity, ethical concerns have driven much of fish welfare research and any claim that welfare is a purely empirical concept may lead to the production of information that has no relevance to those concerns. Fraser et al. (1997) argue that since public concerns cover all 3 aspects of welfare (feelings, function and rights) scientists must incorporate them into their research if they are to provide appropriate guidance for ethical debate.

Rights-based views of ethics can be difficult to equate with feelings- or function-based views. For example, fin damage is a common cause of poor welfare in farmed fish; one solution might be to breed fish without fins. These fish might not behave naturally but would not necessarily show increased levels of disease or injury and might grow very well provided that food could be supplied to them in an appropriate manner. Many people would consider this to be unacceptable without necessarily having a clear idea of the ethical framework underpinning their stance i.e. that fish have rights. Appleby (1999) discussed 2 papers reviewing the first cloned mammal (Dolly the sheep) from the 
perspective of function and rights; the ethics associated with selective breeding and bioengineering was also discussed by Christiansen \& Sandøe (2000) and Lassen et al. (2006). Rights-based definitions of welfare have led to some extreme ethical stances which consider any form of livestock farming to be unacceptable (Francione 2005). Such extreme stances do not appear to be prevalent, since we still have livestock farming and since large quantities of farmed meat are consumed worldwide (FAO 2004).

It is important to remember that much of this debate regarding fish and animal welfare has occurred in the context of western cultures and does not necessarily reflect the concerns or ethics of other cultures. For example, Buddhism has very definite views on animal welfare and, unlike western cultures where humans are commonly seen to have special worth, Buddhist teaching maintains that humans do not have a special place and one should refrain from harming or killing any living creature. The Qur'an (ch. 6 v. 38) also refers to the place of animals and has been variously translated as 'There is not an animal (that lives) on the earth, nor a being that flies on its wings, but (forms part of) communities like you' or 'There is not an animal in the earth, nor a flying creature flying on two wings, but they are peoples like unto you' (www.usc.edu/dept/MSA/quran/). Cultural and religious attitudes to slaughter have also been the subject of considerable and heated debate (Grandin \& Regenstein 1994).

Farmers, researchers and legislators have expended a great deal of time and effort attempting to assess and safeguard fish welfare, but for the most part this has not involved consultation with society at large. It is imperative that we now identify those concerns that have not yet been addressed, in order to engage a wider range of stakeholders in constructive debate. Reflection on the means by which welfare is assessed is a first step to identifying the gaps in our current understanding.

\section{ASSESSING FISH WELFARE}

There is no gold standard for determining animal welfare in terrestrial animals (Spoolder et al. 2003), partly because the method of assessment depends on one's definition of welfare. In farmed aquatic animals defining welfare is, if anything, more challenging than in terrestrial farm animals due to their poikilothermic physiology, ability to adapt to a variety of environmental challenges and the difficulty of making meaningful behavioural observations under farm conditions. In the absence of an agreed definition of welfare, one approach would be to collect information relevant to as wide a range of definitions as possible.
Monitoring welfare as defined by function-based definitions is relatively easy, as methodologies for monitoring the function and performance of animals have been developed over many years in both fundamental and applied biology. Monitoring of feelings, on the other hand, is more challenging, though animal feelings may be accessible through behavioural observations and preference testing. Monitoring welfare on the basis of rights requires an understanding of the nature or evolutionary adaptations of the fish and the farming system within which it is kept. Whichever combination of these 3 approaches is taken, the purpose for which welfare is being assessed is also important, e.g. daily management compared with periodic or post-slaughter auditing. A further challenge is how to present such diverse information in an accessible format (see 'Presentation of fish welfare information').

As part of a framework providing an ethical account for farming Sørensen et al. (2001) described 4 criteria for effective welfare indicators: these should (1) describe important aspects of what matters from the point of view of the animals, (2) encompass changes over time, (3) be capable of being influenced by decisions and actions taken by the individual farmer, and (4) be measurable in a relatively easy and cost effective manner.

While these are useful guidelines, with criteria 2, 3 and 4 applying to most current schemes for assessing farmed fish welfare, they are not adequate for assessing fish welfare without adaptation. It is difficult to determine 'what fish want' or to fulfil the first of Sørensen et al.'s criteria, because preference testing under field conditions has not been attempted and may be very difficult to achieve.

Some people have argued that we should only study welfare from a functional perspective, as feelings are not accessible through scientific enquiry (e.g. Kennedy 1992, discussed in Fraser et al. 1997). This is a reflection of a positivist ethical stance (e.g. Kolakowski 1968) and has led others to claims that science cannot shed light on the subjective experience of animals (Rollin 1990). However, Dawkins (2003) and Weary \& Fraser (1995) have argued convincingly for the role of behavioural observations in providing an honest insight into the subjective experience of the animal, whilst cautioning that this requires very clear thinking to avoid misinterpretation. Fraser et al. (1997) argue that even if our concerns about animal welfare are based on assumptions about their subjective experience and capacity to suffer, it is not possible to address many important ethical questions regarding subjective experience empirically and perhaps never will be. Also Sandøe (1996) argued that consideration of the subjective experience of the animal does not help us to measure or assess welfare; at best it can help clarify what welfare is. 
There have been some very successful attempts to integrate the various categories of welfare; for example Dawkins (2003) discussed 2 questions (Are they healthy? Do they have what they want?) encapsulating the feelings- and function-based definitions of welfare but still failing to incorporate rights-based views. Concepts such as the 5 freedoms i.e. freedom from hunger and thirst, from environmental challenge, from disease and injury, from behavioural restriction and from mental suffering (Anonymous 1992), or subsequently the 5 domains (Mellor \& Reid 1994, Mellor 1999), are useful for integrating the 3 categories of welfare but cannot easily be applied to fish (Huntingford et al. 2006).

In order to assess all 3 categories of welfare definitions, information has to be collected on a wide range of aspects relevant to the fish and the system in which they are farmed. This may include descriptive and contextual information accompanied by measurements, where appropriate. To ensure that the task of assessing welfare is achievable and cost effective, we should when possible avoid assessing more than one from any group of highly correlated variables. Even with a reduced set of observations from measurable aspects of welfare, we still run into the problem of multiple outcomes. In many cases, data from biological welfare studies have many more dependent than independent variables, making analysis and interpretation complex. Approaches to this complexity are discussed by Spoolder et al. (2003), and an additional multivariate technique was proposed by Turnbull et al. (2005). The use of a multivariate technique such as Principal Components Analysis (PCA) provides the means to interpret complex data relating to welfare but it does not necessarily provide a means to monitor or demonstrate acceptable welfare standards. PCA is unlikely to produce the same balance of parameters with data from different farms. To identify parameters that can be used to understand welfare on commercial fish farms, it is first necessary to understand the relationship between the variables and then identify affordable, practical indicators that give a reasonable indication of the larger range of more complex or expensive indicators.

An additional issue that has to be considered in aquaculture is the very large sizes of the populations. One perspective is that the severity of a welfare problem is related not only to the nature of the infringement but also to the duration and the numbers affected. Dawkins (2006) has suggested that an epidemiological approach (studying patterns in populations) is necessary to deal with welfare problems of large farmed populations of animals. Such epidemiological or population based studies of farmed fish welfare are exemplified by Juell \& Fosseidengen (2004), Jones et al. (2005), and Turnbull et al. (2005).

Research is continually providing opportunities for assessing more variables potentially relevant to wel- fare; however, if the epidemiological argument is sound then these have to be applicable at a population level without being prohibitively expensive. For example, indwelling catheters might provide very accurate data on the stress response experienced by an individual fish but this does not provide information that is valuable at the level of the population. Assays based on water cortisol levels have considerable potential to produce valuable population level data but these are not yet practicable (Ellis et al. 2004). Therefore, we are restricted to point-source samples of cortisol and it is arguable whether such samples provide any valuable insight into the welfare state of the fish. However, there is still a great deal of pressure from funding bodies and reviewers to examine at least a limited aspect of the physiological stress response.

The value and limitations of the various approaches to studying and assessing fish welfare status must be appreciated by those carrying out the studies and assessments as well as those with an interest in their outcomes. This can only be achieved through communication of the relevant information in a form that provides a clear understanding for all those concerned,

\section{PRESENTATION OF FISH WELFARE INFORMATION}

Whatever form of assessment is conducted and for whatever purpose, presentation and interpretation of the information is always a challenge. There is a wide variety of information relevant to the various concepts of welfare, ranging from a description of the basic biology of the fish and the farm system to data from specific targeted forms of health assessment. In order to evaluate this information and debate its moral implications it is necessary to present the evidence in an accessible format. Fraser et al. (1997) presented a model for conceptualising 3 areas of ethical concern which together define the subject matter of animal welfare science. Their proposal was that these 3 areas represent the following circumstances where the adaptation of the animal does not correspond to its current environment: (1) the animal possesses an adaptation that no longer serves a significant function in its current environment, (2) the environment poses challenges for which the animal has no adaptation and (3) the animal has adaptations appropriate to its environment but these prove inadequate. Using this as a basis we have developed a template for presentation of information, which, rather than representing areas of concern, relates to the various concepts of farmed fish welfare (Fig. 1, Table 1).

The biological function and behaviour of the fish may be evident from the information contained within 


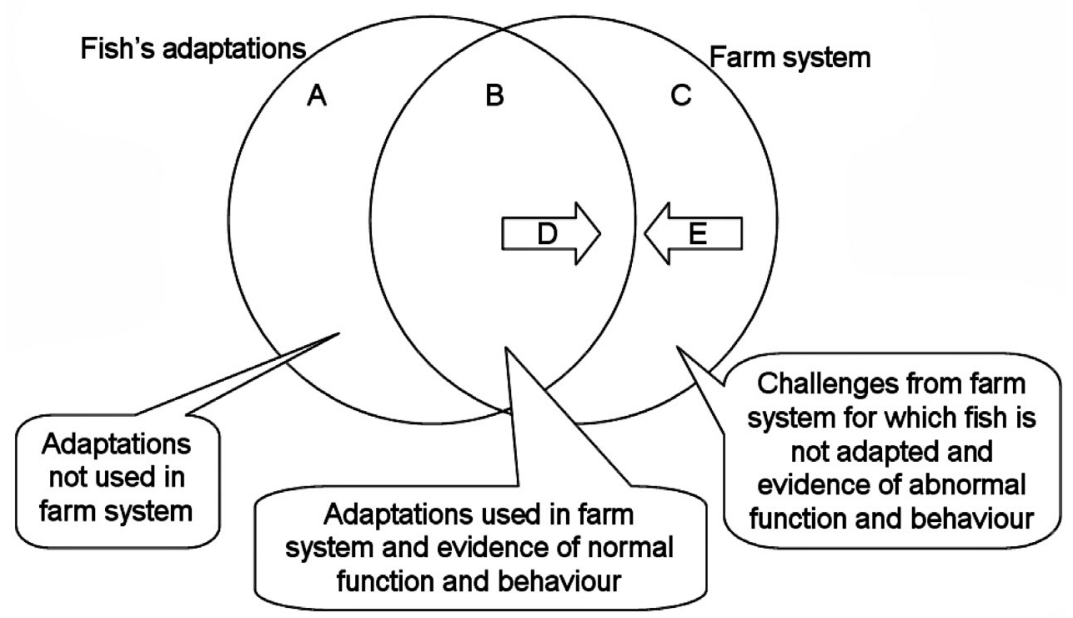

D Factors increasing risk of exposing fish to challenges for which it is not adapted

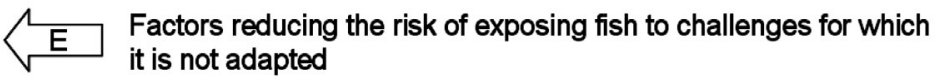

Fig. 1. Proposed template for the presentation of information related to farmed fish welfare. The left circle represents the fish's adaptations and the right circle the farming system. The 5 areas A, B, C, D and E can be populated by information about the nature of the fish, its adaptations and descriptors of the farming system (see Table 1). Subsequently, specific information from welfare assessments can be used to provide additional content for B, C, D and E this template although what is considered to be normal or abnormal in any specific context is a topic for debate. Data on present norms can be collected and findings from individual farms presented within this template. The norms must take account of the farming system; this does not imply that every farm must have its own standards but that significant differences between farming systems should be acknowledged. For example, UK trout farms might be divided into the categories described in Table 2 .

Stocking density is an example of data that might be entered into the template. To take an example from another farming system, there is empirical evidence from a range of functionbased welfare indicators that Atlantic salmon Salmo salar in marine cages do not suffer any adverse effect from stocking densities up to $22 \mathrm{~kg} \mathrm{~m}^{-3}$, but when this density is exceeded there is a correlation between increasing stocking density and deteriorating welfare

Table 1. Examples of the type of information that may be presented in the 5 categories A, B, C, D and E in Fig. 1

A. Adaptations not used in the farming system: Migration / Territoriality / Predator avoidance / Predation / Some reproductive strategies

Some of these adaptations might still be used in the farming system, for example, if predators are not excluded or if the food is supplied as a defensible resource.

B. Adaptations used in the farming system and evidence of normal function and behaviour:

Physiological adaptations:

Adaptations to fluctuations in temperature, salinity and oxygen levels / Appropriate temperature, salinity and dissolved oxygen (DO) ranges

Disease adaptations:

Absence of clinical signs of disease / Absence of pathologies / Presence of some non-virulent diseases, e.g. Viral Haemorrhagic Septicaemia in brown trout Salmo trutta may not be a major threat to health or welfare

Behavioural adaptations:

Shoaling

Growth and production parameters:

Normal mortality rates / Normal growth / Normal condition factor

Husbandry procedures:

Grading etc. conducted in a manner likely to minimise damage and stress

Welfare indices:

Good fin score
C. Challenges from the farming system for which fish is not adapted and evidence of abnormal function and behaviour: Physiological adaptations:

Inappropriate temperature, salinity or DO levels

Disease adaptations:

Presence of clinical signs of disease / Presence of pathologies / Presence of potentially harmful diseases, e.g. Viral Haemorrhagic Septicaemia in rainbow trout Oncorhynchus mykiss

Growth and production parameters:

High mortality rates / Slow growth / Low or high condition factor

Husbandry procedures:

Grading etc. conducted in a manner likely to cause stress or damage

Welfare indices:

Bad fin scores

D. Factors increasing risk of exposing fish to challenges for which it is not adapted:

Low water supply or high loading rates / Poor diet / Endemic diseases / Evidence of predator activity without scope for stock to flee or hide

E. Factors reducing the risk of exposing fish to challenges for which it is not adapted:

Contingency planning / Adequate staff training / System monitoring equipment, e.g. DO with DO supplementation / Regular monitoring of the fish's condition / Protection from predators 
Table 2. Classification of the major types of UK trout farms. These broad categories could be used for setting acceptable standards to safeguard farmed fish welfare; prod: production

\begin{tabular}{|lccc|}
\hline System & Water type & Table prod & Restocking prod \\
\hline Cage & Hard & $O$ & $U$ \\
& Soft & $P$ & $V$ \\
Pond & Hard & $Q$ & $W$ \\
& Soft & $R$ & $X$ \\
Tank/ & Hard & $S$ & $Y$ \\
raceway & Soft & $T$ & $Z$ \\
\hline
\end{tabular}

(Turnbull et al. 2005). Therefore for Atlantic Salmon in marine cages, stocking densities up to $22 \mathrm{~kg} \mathrm{~m}^{-3}$ would be entered into B in the template (Fig. 1), whereas stocking densities above $22 \mathrm{~kg} \mathrm{~m}^{-3}$ would be entered into $\mathrm{E}$, since stocking density on its own is not evidence for poor welfare but is associated with an increased risk of poor welfare.

In the absence of empirical data on motivation and preferences, the impact of the presented information on the subjective experience of the fish is a matter of personal opinion. Similarly, whether and to what extent the farming system infringes any rights fish may have is dependent on the ethical perspective of the person evaluating the data. Therefore, this template will not help to decide what forms of farming various stakeholders consider acceptable but it will at least present the relevant information and provide a focus for discussion. Part of that discussion would inevitably include resolving conflicts between opposing interests or priorities.

\section{BALANCING FISH WELFARE AND OTHER INTERESTS}

Once we have assessed or collected information relevant to fish welfare it is necessary to evaluate that information and decide if the level of welfare is acceptable. The information must first be presented in a format that allows discussion, and then moral decisions must be made that will provide the basis for regulation, monitoring and best practice guidelines. There is the need to balance not only welfare against other priorities but also the different aspects of welfare and various routes towards improved welfare.

It is not always clear who is demanding improved welfare standards for farmed fish (e.g. Ellis et al. 2002, Turnbull et al. 2005, Huntingford et al. 2006). In a Dutch study (Frewer et al. 2005), it appeared that consumers were concerned with providing good health and living conditions for pigs and fish but did not wish to learn about the details of production and slaughter.
In fact, it was suggested that informing consumers of details of production might have a negative effect on sales and consumption. Dutch consumers were concerned in a non-specific manner with the health and living conditions of the animals and were more concerned for the welfare of pigs than fish. It was not clear if this was due to unfamiliarity with aquaculture practices or the opinion that pigs have greater welfare needs. The consumers involved in the study also expressed more concern for environmental issues related to fish as opposed to pig production. While this was not based on any factual evidence for the relative environmental impacts of the industries, such consumer concerns should be incorporated into any welfare standards. This study has very important implications for the marketing of any measures to improve or safeguard welfare. Consumers may be reluctant to get involved in the details of developing welfare systems but their concerns must be addressed to sustain and develop markets.

In a recent study of stakeholders' opinions regarding fish welfare in the British trout farming industry (North et al. in press) it was found that the agenda was largely being driven by NGOs with the large retailers also bringing pressure to bear on farmers. The study showed that farmers had a very positive and proactive attitude to fish welfare and were often exceeding the welfare standards required by legislation and the market. The UK aquaculture industry identified welfare as a key research priority and was using a significant amount of its research budget to support fish welfare research.

The process of deciding whether welfare standards are acceptable may be clarified through the insight of moral philosophers, but the eventual decisions lie with society. People often have emotive responses to welfare issues, which can easily lead to misunderstandings, inconsistent standards and resistance to change. If debate concerning fish welfare consists of nothing more than various groups expressing their feelings or beliefs, then there is little hope of meaningful discussion or understanding. However, examination of the ethical theory underpinning such beliefs can lead towards more effective communication and even a practical compromise (Huntingford et al. 2006). Some moral philosophers have proposed the adoption of a single ethical stance to provide a consistent and logically justifiable approach to ethical questions. In the real world such a single stance can lead to irreconcilable contradictions (Appleby 1999); as a result people generally adopt a variety or combination of ethical stances on a day-to-day basis. A recent series of discussion with stakeholders in the UK trout farming industry demonstrated such complex ethical stances to fish welfare (North et al. in press). Authors such as Fraser (1999) and Appleby (1999) have 
provided frameworks that have significantly improved the clarity of thought regarding welfare and have improved communication between groups with disparate attitudes to welfare.

Superficially, stakeholders in aquaculture appear to subscribe to a semi-utilitarian ethic, where benefits and disadvantages can be traded off. This is obvious from the very existence of aquaculture to supply fish for human consumption and sport. At least some consumers are prepared to farm animals including fish, provided that it is done in a manner that they feel is humane (Frewer et al. 2005). Even fish welfare research, where some fish are subjected to adverse conditions in an attempt to improve the welfare of a larger number of fish, implies that we do not consider the rights of the individual to be paramount. While we should reduce the number of live animals used, refine the experimental techniques which use live animals and replace those techniques where possible, this is still evidence for a semi-utilitarian ethical stance where such trade-offs are acceptable. However, some people still apply a rightsbased ethic to animal welfare (deontology discussed in the context of animal welfare by Christiansen \& Sandøe 2000). Some people maintain that the ends cannot justify the means and in the most extreme form would abolish all farming of animals for food or sport (Francione 2005). There are, however, more moderate views, which accept that compromises should be made but that there are minimum standards of care (environment and husbandry) that must be provided. There is no doubt that trade-offs are made between conflicting interests (discussed by Jensen 1996).

If we accept that trade-offs are necessary, problems still arise when we try to quantify the various benefits and harms (Christiansen \& Sandøe 2000). There is no agreement on how we should weigh the concern for welfare of fish against the human interests involved (Huntingford et al. 2006), although a system has been developed to make the process of balancing interests transparent through ethical accounting (Jensen \& Sørensen 1999, Sørensen et al. 2001). While this system provides a framework to balance often conflicting concerns regarding fish welfare, economic production, food safety and environmental impact, it does place considerable additional training and administrative burden on the farmer. While these debates regarding the nature of fish welfare and how to resolve conflicting interests continue there is still the need to safeguard the welfare of farmed fish.

\section{SAFEGUARDING THE WELFARE OF FISH}

We have already discussed assessment of fish welfare and a template for presentation of the information.
However, these tools have to be applied in order to safeguard fish welfare.

One approach might be to agree that we can only safeguard what we can measure. This may, however, not produce any real improvement in welfare, for several reasons. The results of welfare assessment will be biased to the aspects reflected by the welfare indices used (Spoolder et al. 2003). Also, the parameters that can be measured may not have a simple relationship with welfare, for example the measurable aspects of physical arousal during coitus or due to fear have many similarities (Rushen 1991, Toates 1995) but with very different implications for welfare. Finally, we cannot always predict the outcome of our actions even if we have evidence from small-scale experimental studies; therefore, strategies to improve welfare have to be tested on real populations (Jones et al. 2005).

Researchers, farmers and legislators should appreciate and, where possible, incorporate as wide a range of views as possible into systems to safeguard welfare. If they do not, they run the very serious risk of failing to make any progress in the eyes of some stakeholders. The debate over stocking density provides an example. One of the authors of this paper was involved in a study that earnestly attempted to explore the effects of stocking density on Atlantic salmon in commercial marine cages (Turnbull et al. 2005). We maintain that this study produced valuable and valid results but there are 2 problems with the approach taken. Firstly, we did not have, and still lack, any way to measure positive experiences in farmed fish. Secondly, if one feels that keeping Atlantic salmon in cages in some way infringes their right to spend a portion of their life swimming freely in the sea then all this work will do nothing to convince one that stocking densities up to $22 \mathrm{~kg} \mathrm{~m}^{-3}$ represent acceptable welfare. What this study did achieve was to demonstrate that to the best of our abilities we could find no evidence for an adverse effect of increasing stocking density up to a certain point on a wide range of function-based welfare indicators. The other aspects of positive experiences and the rights of the fish are as yet un-measurable but should not be ignored. These issues can only be addressed through appropriate empirical studies and constructive dialogue, and there are multinational initiatives to facilitate such dialogue (e.g. European COST Action 867 www.fishwelfare.com/ and Canadian www.aquanet.ca/).

Very poor welfare (e.g. disease, poor growth and mortalities) is not cost-effective for the farmer, so even the farms that have relatively poor fish welfare have found a balance between welfare and productivity. If society wishes to persuade farmers who are attempting to run a business to improve their fish welfare standards, evidence for cost-effective improvements in welfare may 
prove more persuasive than moral argument. Therefore, generating and modelling the relevant economic arguments should be seen as a priority. It is important to emphasise that there is not necessarily any correlation between high productivity and poor welfare; we do not have the data to test such a hypothesis.

Farmers who are prepared to improve or safeguard the welfare of their fish must be encouraged. If an auditing or monitoring system puts them at a competitive disadvantage then only those with lesser concerns for welfare will survive and the overall welfare standards will drop. Any scheme must aim for improvements rather than act as an incentive to dishonest participation and has to be flexible enough to accommodate new research findings or shifts in moral concerns (Mellor \& Stafford 2001).

Efforts to improve or safeguard welfare must be governed by clear aims while not becoming counterproductive through rigid application of rules. For example, if detection of an infection will result in destruction of the stock and closure of the hatchery without compensation, then farmers are likely to find ways to avoid detecting or reporting the disease. Any system of monitoring and control must have a means of enforcing compliance but penalties should be a last resort. The only way such a scheme is likely to be successful is if it is developed by the farmers or in a manner which gives them ownership and responsibility for the scheme. There are examples for terrestrial animals such as the Food Animal Initiative (www.faifarms.co.uk/index.html) and from aquaculture such as the quality schemes of the British Trout Association (www.britishtrout.co.uk/) and Scottish Salmon Producers Organisation (www.scottishsalmon.co.uk/).

What aspects of fish welfare can we safeguard? The nature of the farming system will determine how far the rights of the fish are accommodated. Pressure to change the system might come from legislation or through the market chain. In this paper it is not possible to discuss how diverse farming systems might be changed to accommodate the adaptations of fish; instead we will describe the main elements of a scheme to safeguard fish welfare within existing farming systems. The template described in Fig. 1 could be used to facilitate identification of threats to welfare and measures to prevent them. However, questions remain, such as where to draw the line between $B$ and $C$, and how far we are prepared to let fish stray into the area for which they are not adapted. The template does not produce the answers to these problems but presents the information in a format that should facilitate informed discussion.

Again referring to Fig. 1 and Table 1, systems should be in place to ensure that the fish are not exposed to challenges from a farm system for which they are not adapted (C). Any risks of exposing the fish to such challenges (D) should be identified and contingency plans put in place to reduce those risks (E). Fish also have to be monitored to detect deteriorating welfare since any rational strategy for safeguarding welfare has to focus on prevention rather than just detection of bad welfare. While there is a wide range of potential measures to monitor aspects of welfare, many are only suitable in a research context. Some, however, can be used in many types of commercial farms and provide valuable information. Monitoring of the fish and productivity parameters can provide useful information for controlling daily management, audit purposes and retrospective analysis of the farming system. Production indices, while retrospective, are monitored regularly on many farms e.g. survival (mortalities), growth, food conversion ratio and condition factor. Such production parameters have to be interpreted in the context of the farming system, life stage and environmental factors. For example, the behaviour of the fish (mostly during feeding) can provide a useful guide to the health of the population but is determined not only by the species and farming system but also by other factors such as temperature and photoperiod (Talbot \& Higgins 1984). Most farmers would regularly examine some fish in order to detect the presence of pathologies and to estimate growth rates but in the event of a problem arising it may be necessary to undertake target sampling to identify a specific environmental, nutritional or infectious disease. Procedures to identify when such sampling is necessary and mechanisms to have the samples analysed and the results acted upon should be part of a veterinary health plan or similar contingency plan. Post-harvest data from processors is another source of information, especially on physical abnormalities or pathological lesions. To be of value there has to be effective traceability but this could potentially be used either for auditory purposes or for retrospective analysis of the farming system.

Appropriate farm practices could include staff training, husbandry systems for daily management, handling and slaughter. Contingency planning combined with a veterinary health plan would provide preventative strategies and ensure an adequate response to situations threatening many aspects of fish welfare. For example, if there were the risk of excessively high water temperatures at certain times of the year, staff should monitor dissolved oxygen levels and behaviour of the fish closely at this time of year for signs of hypoxia and know how to respond. The response would include reduction in feeding and additional water exchange, aeration or oxygenation depending on the system and perhaps a reduction in stocking densities prior to the period of risk. They should also monitor weather forecast for changes that might lead to low oxygen levels, e.g. cloudy weather can reduce oxygen production by plankton in pond systems. 
While such strategies might not fulfil everyone's requirements for safeguarding fish welfare they will certainly greatly reduce the risk of fish being subjected to conditions for which they are not adapted. This will safeguard many functional aspects of welfare and, if fish can suffer, protect them from the suffering associated with many infectious and non-infectious pathologies.

\section{CONCLUSION}

The demand for enhanced farmed fish welfare does not necessarily originate from an understanding of the biological and philosophical arguments but from emotive responses (Morris 2000, Mellor \& Stafford 2001). If we are to make progress then we have to understand our own and others' viewpoints (Appleby 1999). There has been a great deal of debate and sometimes open hostility between people with differing approaches to welfare such as animal welfare pressure groups (Lymbery 2002) and farmers' representatives. This argument has continued in a recent advertising campaign (Johnston 2006). It has been suggested (Appleby 1999, Fraser 1999) that progress has been inhibited by a fundamental lack of common ground, i.e. people are debating different questions. Compromise or consensus can only be achieved through understanding and this, in turn, requires effective presentation of information and constructive dialogue. Through improved understanding of all aspects of welfare we will increase our capacity to safeguard the welfare of farmed fish in the eyes of a wider range of stakeholders whatever their perspective on welfare. To date if your definition of welfare is 'Are these fish healthy and happy?' then we have probably made considerable progress over the last $10 \mathrm{yr}$. If the concern is 'Should we keep aquatic animals in captivity for our benefit?' then we have probably failed to adequately consider this problem.

Acknowledgements. We have cited all sources to which we referred in this manuscript. Inevitably some works, which have shaped our understanding in the past, have been omitted from the reference list, and we apologise to those authors. There are other people who we must thank for helping us to understand welfare: Colin Adams, Victoria Braithwaite, Felicity Huntingford, Anders Kiessling, James Kirkwood, Alistair Lawrence, Sandra Marshal, Nick Read, Peter Sandøe, Ed Varley and Bob Waller. Thanks especially to Ben North and Craig McIntyre for comments on the manuscript.

\section{LITERATURE CITED}

Anonymous (1992) FAWC updates the Five Freedoms. Vet Rec 131:357

Anonymous (2006) Recommended whitefish quality guidelines for fishing and processing operations. Alaska Seafood Marketing Institute, Juneau, AK. Available at: www.alaskaseafood.org/fishingprocessing/whitefis.htm Appleby MC (1999) Tower of Babel: variation in ethical approaches, concepts of welfare and attitudes to genetic manipulation. Anim Welf 8:381-390

Braithwaite VA, Huntingford FA (2004) Fish and welfare: do fish have the capacity for pain perception and suffering? Anim Welf 13:587-592

Broom DM (1991a) Assessing welfare and suffering. Behav Proces 25:117-123

Broom DM (1991b) Animal welfare: concepts and measurement. J Anim Sci 69:4167-4175

Chandroo KP, Duncan IJH, Moccia RD (2004) Can fish suffer? Perspectives on sentience, pain, fear and stress. Appl Anim Behav Sci 86:225-250

Christiansen SB, Sandøe P (2000) Bioethics: limits to the interference with life. Anim Reprod Sci 60-61:15-29

Conte FS (2004) Stress and the welfare of cultured fish. Appl Anim Behav Sci 86:205-223

Dawkins MS (2003) Behaviour as a tool in the assessment of animal welfare. Zoology 106:383-387

Dawkins MS (2006) A user's guide to animal welfare science. Trends Ecol Evol 21:77-82

Ellis T, North B, Scott AP, Bromage NR, Porter M, Gadd D (2002) The relationships between stocking density and welfare in farmed rainbow trout. J Fish Biol 69:493-531

Ellis T, James JD, Stewart C, Scott AP (2004) A non-invasive stress assay based upon measurement of free cortisol released into the water by rainbow trout. J Fish Biol 65: $1233-1252$

Ewbank R (1988) Animal welfare. In: Universities Federation for Animal Welfare (eds) Management and welfare of farm animals. Baillière Tindall, London, $\mathrm{p}$ 1-12

FAO (Food and Agricultural Organisation) (2004) Meat and meat products. In: Food Outlook No. 4, December 2004. FAO, Rome. Available at: www.fao.org/docrep/007/ j3877e/j3877e08.htm

Francione G, (2005) One right for all. New Scientist, 8 October, $\mathrm{p} 24$

Fraser D (1999) Animal ethics and animal welfare science: bridging the two cultures. Appl Anim Behav Sci 65: 171-189

Fraser D, Weary DM, Pajor EA, Milligan BN (1997) A scientific conception of animal welfare that reflects ethical concerns. Anim Welf 6:187-205

Frewer LJ, Kole A, van de Kroon SMA, de Lauwere C (2005) Consumer attitudes towards the development of animalfriendly husbandry systems. J Agric Environ Ethics 18: 345-367

Grandin T, Regenstein JM (1994) Religious slaughter and animal welfare: a discussion for meat scientists. Meat Focus International, March, p 115-123

Huntingford FA, Adams C, Braithwaite VA, Kadri S, Pottinger TG, Sandøe P, Turnbull JF (2006) Current understanding on fish welfare: a broad overview. J Fish Biol 68: $332-372$

Jensen KK (1996) The trade-off between animal welfare and human interests. Acta Agric Scand Sec A Anim Sci 27: 104-108

Jensen KK, Sørensen JT (1999) The idea of 'ethical accounting' for a livestock farm. J Agric Environ Ethics 11:85-100

Johnston J (2006) Freedom salmon ad criticised. Sunday Herald (UK), 30 July

Jones TA, Donnelly CA, Dawkins MS (2005) Environmental and management factors affecting the welfare of chickens on commercial farms in the United Kingdom and Denmark stocked at 5 densities. Poult Sci 84:1155-1165

Juell J, Fosseidengen JE (2004) Use of artificial light to control 
swimming depth and fish density of Atlantic salmon (Salmo salar) in production cages. Aquaculture 233:269-282

Kennedy JS (1992) The new anthropomorphism. Cambridge University Press, Cambridge

Kolakowski L (1968) The alienation of reason: a history of positivist thought (translated by N. Guterman) Doubleday, New York

Lassen J, Gjerris M, Sandøe P (2006) After Dolly-ethical limits to the use of biotechnology on farm animals. Theriogenology 65:992-1004

Lymbery P (2002) In too deep-the welfare of intensively farmed fish. Compassion in World Farming, Petersfield. Available at: www.ciwf.org.uk/publications/fish.html

McGlone JJ (1993) What is animal welfare? J Agric Environ Ethics 6, Suppl 2:26-36

Mellor DJ (1999) What determines minimum farm animal welfare standards - animals' actual needs, animals' perceived needs or economics? In: Proc 16th Annu Sem Soc Dairy Cattle Veterinarians of the NZVA. Publ. No. 1192, NZVA Foundation for Continuing Education, Massey University, Palmerston North, p 143-152

Mellor DJ, Reid CSW (1994) Concepts of animal well-being and predicting the impact of procedures on experimental animals. In: Baker RM, Jenkin G, Mellor DJ (eds) Improving the well-being of animals in the research environment. Australian and New Zealand Council for the Care of Animals in Research and Teaching, Glen Osmond, p 3-18

Mellor DJ, Stafford KJ (2001) Integrating practical, regulatory and ethical strategies for enhancing farm animal welfare. Aust Vet J 79:162-168

Morris M (2000) Animal care ethics, ANZCCART, and public perceptions of animal use ethics. J Agric Environ Ethics 13:249-257

North BP, Ellis T, Knowles T, Bron JE, Turnbull JF (in press) The use of stakeholder focus groups to identify indicators for the on-farm assessment of trout welfare. In: Branson EJ (ed) Fish

Editorial responsibility: Anne Berit Skiftesvik, Storebø, Norway welfare. Blackwell Publishing, Oxford

Rollin BE (1990) The unheeded cry. Oxford University Press, Oxford

Rose JD (2002) The neurobehavioural nature of fishes and the question of awareness and pain. Rev Fish Sci 10:1-38

Rushen J (1991) Problems associated with the interpretation of physiological data in the assessment of animal welfare. Appl Anim Behav Sci 28:381-386

Sandøe P (1996) Animal and human welfare-are they the same kind of thing? Acta Agric Scand Sec A Anim Sci 27: $11-15$

Sneddon LU, Braithwaite VA, Gentle MJ (2003a) Do fish have nociceptors: evidence for the evolution of a vertebrate sensory system. Proc R Soc Lond B 270:1115-1121

Sneddon LU, Braithwaite VA, Gentle MJ (2003b) Novel object test: examining nociception and fear in the rainbow trout. J Pain 4:431-440

Sørensen JT, Sandøe P, Halberg N (2001) Animal welfare as one among several values to be considered at a farm level: the idea of an ethical account for livestock farming. Acta Agric Scand Sec A Anim Sci 30:11-16

Spoolder H, de Rosa G, Hörning B, Waiblinger S, Wemelsfelder F (2003) Integrating parameters to assess on-farm welfare. Anim Welf 12:529-534

Talbot C, Higgins PJ (1984) Effects of pre-prandial and postprandial starvation on meal size and evacuation rate of juvenile Atlantic salmon, Salmo salar L. J Fish Biol 25: $551-560$

Toates FM (1995) Stress: conceptual and biological aspects. John Wiley \& Sons, Chichester

Turnbull JF, Bell A, Adams C, Bron J, Huntingford FA (2005) Stocking density and welfare of cage farmed Atlantic salmon: application of a multivariate analysis. Aquaculture 243:121-132

Weary DM, Fraser D (1995) Calling by domestic piglets: reliable signals of need? Anim Behav 50:1047-1055

Submitted: September 12, 2006; Accepted: January 22, 2007 Proofs received from author(s): March 24, 2007 